\title{
MEASUREMENTS TO SPACE DEBRIS IN 2016-2020 BY LASER SENSOR AT BOROWIEC POLAND
}

\author{
Adrian SMAGŁO, Paweł LEJBA, Stanisław SCHILLAK, \\ Tomasz SUCHODOLSKI, Piotr MICHAŁEK, \\ Stanisław ZAPAŚNIK, Jacek BARTOSZAK \\ Space Research Centre, Polish Academy of Science, Astrogeodynamic \\ Observatory, Borowiec, Poland \\ e-mail: asmaglo@cbk.poznan.pl
}

\begin{abstract}
In 2014, a significant upgrade was made to the Borowiec (BORL 7811) laserranging system, which is the part of Space Research Centre of the Polish Academy of Sciences (SRC PAS). Two high-energy lasers modules were installed. First is the EKSPLA PL-2250, used for tracking objects equipped with retroreflectors. Second is the Continuum Surelite III, dedicated to the tracking of space debris without retroreflectors. In 2016, the BORL station joined the space debris tracking laser group and, since then, is tracking systematically inactive/defunct satellites and typical rocket bodies from LEO regime. Today, the BORL is tracking regularly about 80 different space debris objects. The paper presents the activity of the BORL laser station in observations of space debris. The results presented are from years 2016 to 2020. The sum of all passes from this period is almost 2000 , giving over 23000 normal points. Average root mean square error (RMS) of objects with satellite laser ranging-dedicated (SLR-dedicated) retroreflectors ranges $1.5 \mathrm{~cm}-14 \mathrm{~cm}$ and of objects without SLR-dedicated retroreflectors ranges $8 \mathrm{~cm}-222 \mathrm{~cm}$.
\end{abstract}

Keywords: satellite geodesy, SLR, space debris, Borowiec SLR station

\section{INTRODUCTION}

BORL station is currently observing space debris objects and satellites. The results of the SLR observations of satellites are used to determine positions and velocities of the stations (Lejba and Schillak, 2011, Schillak et al., 2021), earth orientation parameters (Sośnica at al., 2014), tidal parameters (Jagoda and Rutkowska, 2016, Jagoda et al., 2016), the ocean tide models (Sośnica, 2015) and study the Earth's gravity field (Sośnica et al., 2012).

The space debris objects are a fast-growing group of space objects. Over the last years, we notice a quick increase in their number. The group of space debris consists of inactive/defunct satellites, rocket bodies, and all the elements from orbital collisions, fragmentation events and anti-satellite tests (ASAT) (Kan, 2007, Milowicki and Johnson-Freese, 2008). Today the number of known space objects on orbits regularly tracked by Space Surveillance Networks is about 28,600 (ESA, 2021). This number of objects contributes to the Kessler syndrome (Kessler and Cour-Palais, 1978). A collision of two objects can generate new debris. Those new elements can cause further collisions and so on. A lot of the space debris are small pieces, which cannot 
be observed like drops of liquids, paint chips and ejected items. The European Space Agency (ESA) estimated by statistical models that about 900,000 of space debris are greater than $1 \mathrm{~cm}$ to $10 \mathrm{~cm}(\mathrm{ESA}, 2021)$.

Observation techniques are divided into two types. First type is an in-situ measurement. This technique is mainly used for obtaining the statistical distribution data of space debris objects up to $1 \mathrm{~cm}$ (Tagawa et al., 2010). Another approach is the remote sensing technique. This is mainly used for ground-based space observation and is divided into two types - radar and optical. Graz SLR station used Quanta Photogrammetry as an optical method for remote detection of micrometeoroid and orbital debris impacts (Kucharski et al., 2020). In 2002, Electro Optic Systems (EOS) Australia started laser tracking of the space debris of size $15 \mathrm{~cm}$ (Green et al., 2002). The Shanghai Astronomical Observatory (SHAO) of the Chinese Academy of Sciences (CAS) in 2008 successfully measured a space debris target, using $40 \mathrm{~W}$ high-power nanosecond laser (Wu et al., 2019). In 2012, the satellite laser station in Graz started first laser-ranging measurements to space debris. The specialists from Graz used a diode-pumped laser with frequency of $1 \mathrm{kHz}, 25 \mathrm{~mJ}$ pulse energy and $10 \mathrm{~ns}$ pulse width (Kirchner and Koidl, 2015). In 2019, Graz SLR station had new laser (200 Hz repetition rate, $532 \mathrm{~nm} / 80 \mathrm{~mJ}$ or $1064 \mathrm{~nm} / 160$ $\mathrm{mJ}$ ) for the tracking of space debris mounted on the telescope (Steindorfer et al., 2019). Currently, Graz station uses a daylight space debris laser-ranging system, which increases the potential observation times (Steindorfer et al., 2020).

The Space Surveillance and Tracking (SST) programme was created to detect and catalogue space debris objects and determine their orbits. In Europe, the forerunner of this system is ESA's Space Debris Office. In 2014, the EUSST Consortium was established. Currently, the consortium consists of eight EU members, including Poland. The whole network covers 51 sensors including radars, telescopes and laser-ranging stations (EUSST, 2021). In 2014, a Space Debris Study Group (SDSG) founded by the International Laser Ranging Service (ILRS) was established. The SDSG was formed to serve as a forum to provide consultation, assistance and help with hardware, software and procedures (SDSG, 2021).

Since second half of 2016, Borowiec Astrogeodynamic Observatory (BORL 7811) is part of a SDSG and SST programme (Lejba et al., 2016). The BORL station has begun the systematic tracking of inactive satellites and rocket bodies from LEO regime (Lejba et al., 2018).

This paper aims to pay attention to difficult problem of space debris SLR observations, especially objects without retroreflectors compared to objects with SLR-dedicated retroreflectors. The paper also presents activity of Borowiec SLR station in this field in the last five years. Laser measurements to space debris are using to orbit determination (Lejba et al., 2020), researching of rotation or tumbling of objects (Kucharski et al., 2017). This allows improving space debris objects' orbits and improve the prediction of future potential collisions. This affects monitoring and building independent catalogue of the laser observations of space debris.

\section{BOROWIEC SATELLITE LASER RANGING SYSTEM (BORL-7811)}

Satellite laser-ranging technique is based on measuring the time interval of propagation of the laser pulse from the laser transmitter to satellite and back to the receiver. From this time interval, the double distance to the tracked object is computed. The laser pulse is first detected by the fast photodiode that starts a time interval counter and laser pulse is transmitted by telescope to the satellite. The laser pulse goes through the atmosphere and is reflected by a space target. The returning pulse is registered by the detector, which stops the time interval counter. Although the measurement principle is simple, the construction of the station is complicated. There are about 40 SLR stations that work in a similar way, but each one is built differently (Pearlman et 
al., 2019). This is due to the fact that each station is built individually. The schematic diagram of the SLR system at BORL is given in Fig. 1.

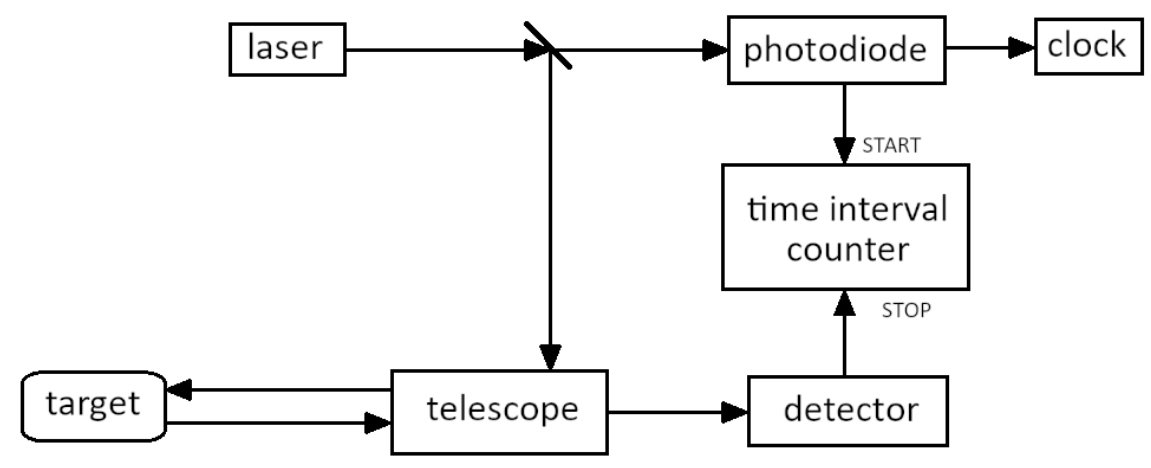

Figure 1. Schematic diagram of the SLR system BORL

The speed of the light in the atmosphere is slower and depends mainly on temperature, pressure and humidity. Before and after the observation session, the calibration measurements are being performed. Calibration determines the value of the distance to a ground target located at an exactly known distance from the intersection of the telescope axis. The difference between the distance measured during calibration and the known distance to target is the calibration correction (Schillak, 2004). Calibration should also be performed for space debris observations. For EKSPLA module, the calibration correction $\Delta c a l$ is on the level of $-62-63 \mathrm{~ns}$; and for CONTINUUM module, the $\Delta$ cal parameter is on the level of $-64-65 \mathrm{~ns}$. The difference between $\Delta c a l$ parameter for both lasers results directly from parameters of their impulses.

The BORL station consists of five main segments, such as the pulsed lasers, the transmitting and receiving telescope, the measuring equipment, the computer system with control software and the time scale.

The sources of the lasers are: Nd:YAG Continuum Surelite III module dedicated to the space debris measurements and Nd:YAG EKSPLA PL-2250 module used for tracking of objects with SLR-dedicated retroreflectors. The main parameters of these lasers are shown in Table 1.

Table 1. The main parameters of BORL's lasers modules

\begin{tabular}{|c|c|c|}
\hline Parameter & Continuum Surelite III & EKSPLA PL-2250 \\
\hline Repetition rate & $10 \mathrm{~Hz}$ & $10 \mathrm{~Hz}$ \\
\hline Pulse energy for $532 \mathrm{~nm}$ & $450 \mathrm{~mJ}$ & $50 \mathrm{~mJ}$ \\
\hline Pulse length & $3-5 \mathrm{~ns}$ & $60 \mathrm{ps}$ \\
\hline Peak power & $112.5 \mathrm{MW}$ & $833 \mathrm{MW}$ \\
\hline Average power & $4.5 \mathrm{~W}$ & $0.5 \mathrm{~W}$ \\
\hline
\end{tabular}

The transmitting-receiving telescope is an azimuth-elevation Cassegrain system telescope with its primary mirror diameter being $65 \mathrm{~cm}$ and secondary mirror diameter being $20 \mathrm{~cm}$. The mount is additionally equipped with a smaller guiding telescope, which allows us to preview the part of the sky and makes it easier to control the laser beam during the observations. The laser beam is transmitted to the telescope from the lasers via the Coudé system.

The measuring equipment consists of a high-speed start Si photodiode FDS025, a STANFORD SR620 time interval counter and a photomultiplier tube (PMT) detector HAMAMATSU $\mathrm{H} 5023$. The time scale is an active hydrogen maser $\mathrm{CH} 1-75 \mathrm{~A}$ providing $10 \mathrm{MHz}$ and $1 \mathrm{PPS}$ 
time signal to laser sensor clock. The entire laser system is controlled by the computer system which is responsible for computing orbital objects ephemeris, controlling laser system during the observations, executing of the system calibration, processing the raw measurements and sending the results to the external database.

\section{RESULTS}

At present, the BORL station is tracking systematically about 80 different space debris objects from LEO regime. There are objects equipped with retroreflectors, such as ADEOS-2, ENVISAT, ERS-1, ERS-2, JASON-1, OICETS, SEASAT-1 or TOPEX/Poseidon, and targets without retroreflectors, such as ESA's ARIANE, US's DELTA and TITAN, China's CZ or Russian's SL rocket bodies. These objects with retroreflectors are inactive/defunct satellites, their missions were (ILRS Past Missions, 2021):

- ADEOS-2-regularly monitoring of the water and energy cycle as a part of global system, quantitatively estimate the biomass and fundamental productivity as part of the carbon cycle, active from 2002 to 2003 ,

- ENVISAT-follow-on mission to ERS-2, active from 2002 to 2012,

- ERS-1 and ERS-2-monitoring Earth's environment and climate changes, monitoring of the Earth's renewable and nonrenewable resources, active from 1991 to 2000 (ERS-1), 1995-2011 (ERS-2),

- JASON-1-monitoring global ocean circulation, discovering the tie between the ocean and atmosphere, improving global climate predictions and monitoring events such as $\mathrm{El}$ Nino conditions and ocean eddies, active from 2001 to 2013,

- OICETS-verifying optical communication with the ESA ARTEMIS mission, active from 2005 to 2009 ,

- $\quad$ SEASAT-1-measuring sea surface height, measuring surface winds, active from 1978 to 1978 and

- TOPEX/Poseidon-exploring ocean circulation and its interaction with the atmosphere, active from 1992 to 2006.

Figure 2 shows the numbers of passes of objects equipped with retroreflectors tracked in 20162020 by BORL station.

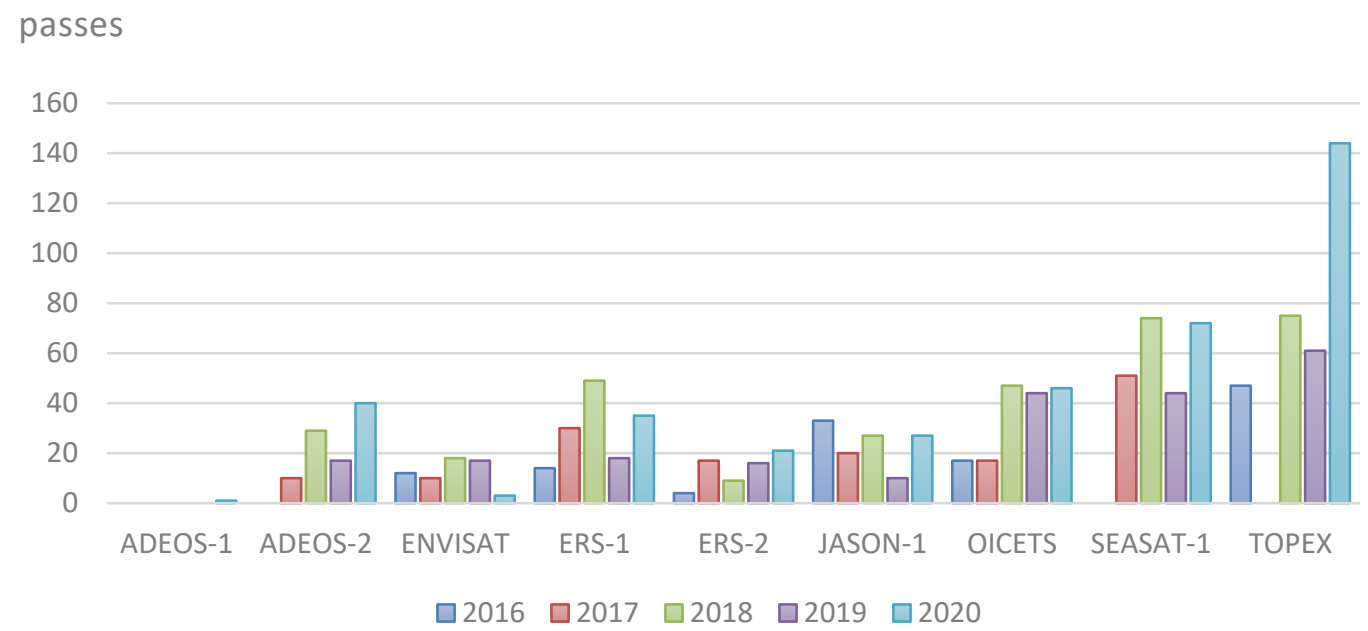

Figure 2. Numbers of passes of objects equipped with retroreflectors tracked in 2016-2020 by BORL station 
Full table, which shows all space debris equipped with retroreflectors observed by BORL station in years 2016-2020, is attached in Appendix 1. Included information are about perigee, apogee and inclination of the orbit, number of successful observed passes, number of received normal points, average value of RMS and number of single measurements for all successful passes. All of these objects were observed by means of picosecond EKSPLA laser module.

Average RMS of all objects ranges from $1.5 \mathrm{~cm}$ to $14 \mathrm{~cm}$ except TOPEX/Poseidon object. TOPEX is a fast tumbling object; it is very well presented in Figure 3. The reason for the high RMS values is that the size of the satellite is large which, combined with tumbling, causes the distance to the LRA is changing permanently. The retroreflector array is a $1.5-\mathrm{m}$ diameter annulus ring comprised of 192 corner cubes mounted in two concentric rings around the altimeter antenna. TOPEX is the most tracked target by Borowiec station in years 2016-2020; the sum of all passes is 378 with 508171 normal points.

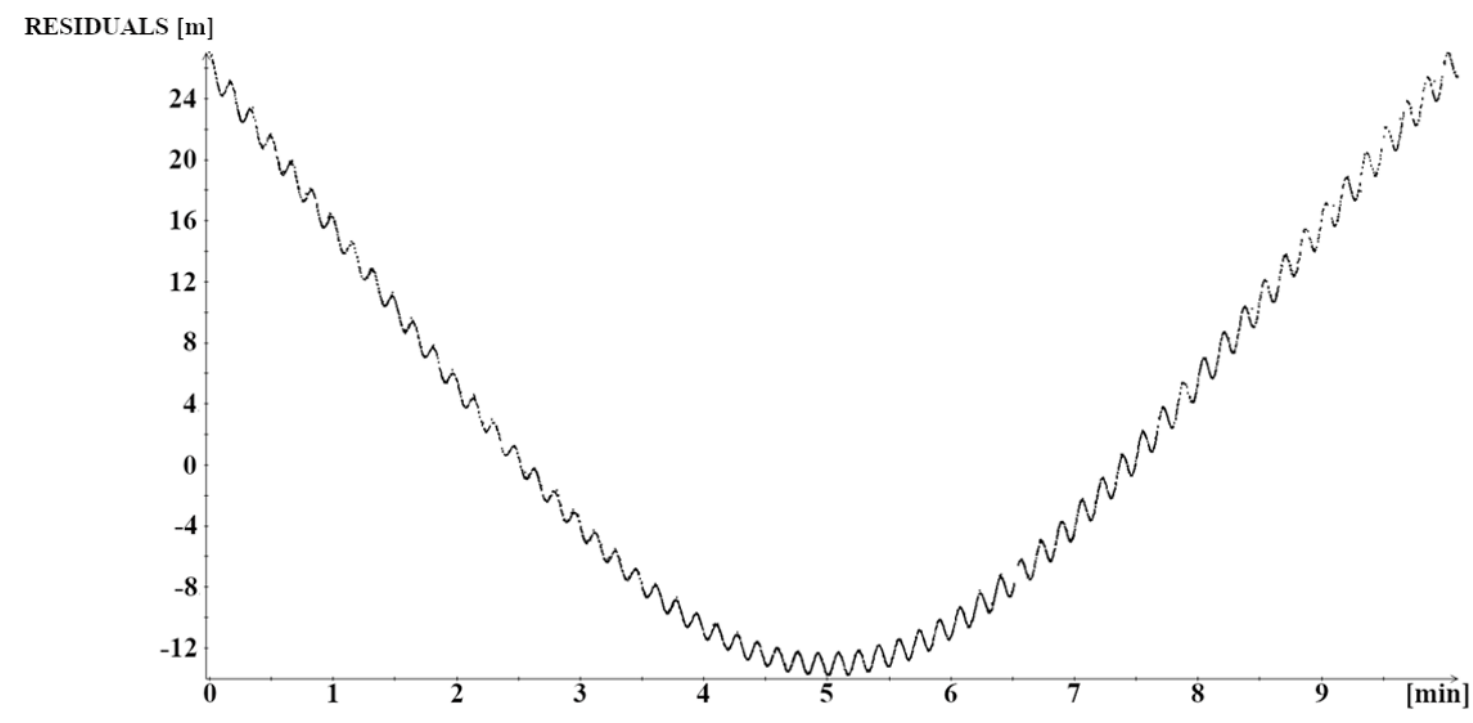

Figure 3. Rotation of defunct TOPEX/Poseidon satellite. Pass on April 24, 2020 00:00 UTC, showing the difference between observation and prediction with 4015 valid returns and with a 1903-2686 distance to the target of $\mathrm{km}$. The pass RMS is $20.9 \mathrm{~cm}$.

The numbers of passes of the objects without retroreflectors tracked in 2016-2020 by BORL station are present in Figure 4. Full table, which shows all space debris without retroreflectors observed by BORL station in years 2016-2020, is attached in Appendix 2. Included information are about perigee, apogee and inclination of the orbit, number of successful observed passes, number of received normal points, average value of RMS and number of single measurements for all successful passes. 


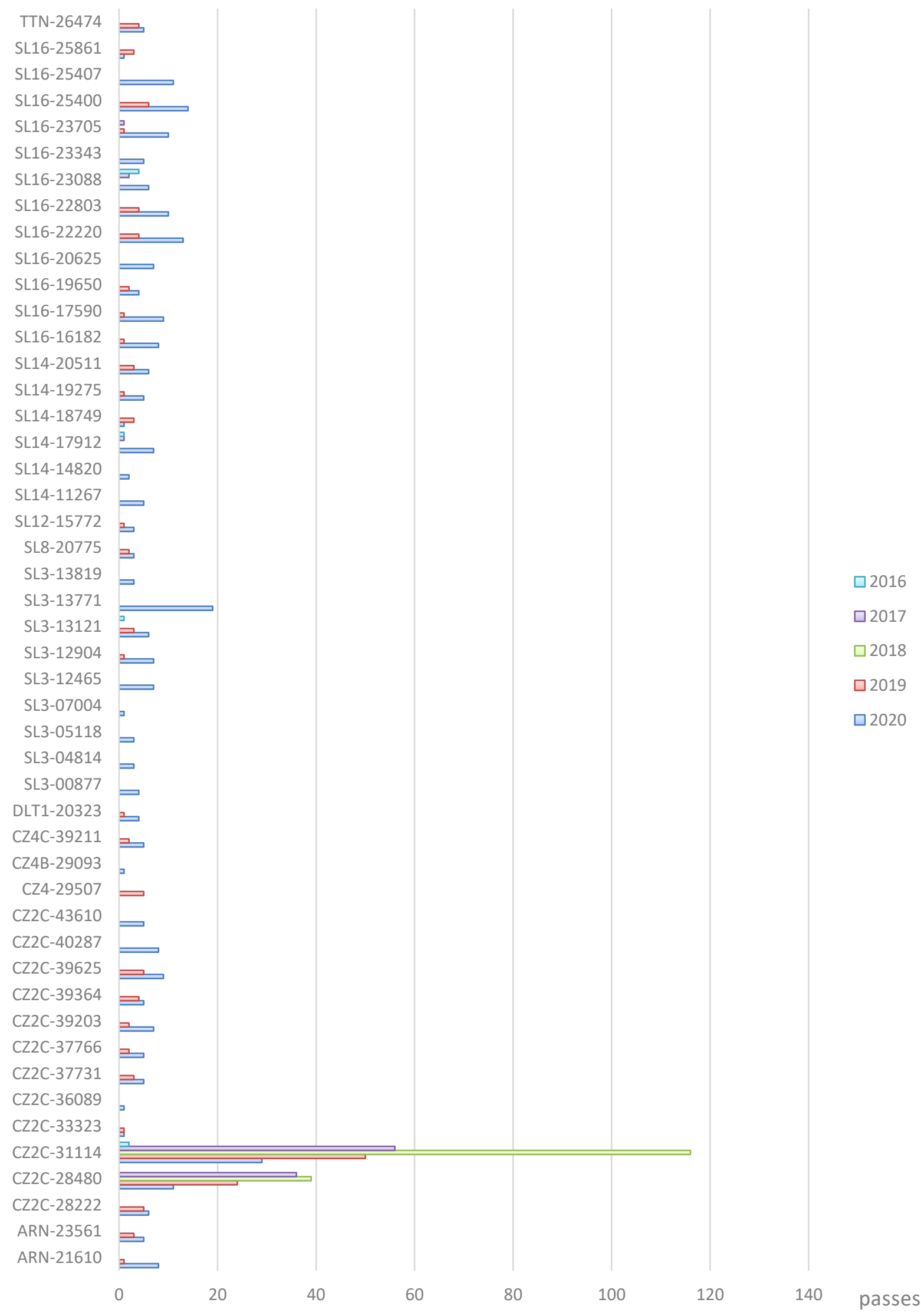

Figure 4. Number of passes of objects without retroreflectors tracked in 2016-2020 by BORL station 
Appendixes 1 and 2 show the numbers of passes, normal points, average RMS and returns. The objects not equipped with retroreflectors are more difficult to measure; therefore, the sum of successful observations in Appendix 2 is 710 as compared to 1226 in Appendix 1. Despite many observations, only a few were successful. The total number of observations of space debris in 2020 is 2169 of which 692 were successful. This shows an efficiency of 32\%. All of these objects were observed with a strong nanosecond laser module, RMS changes from about $8 \mathrm{~cm}$ to even $222 \mathrm{~cm}$. The number of returns from objects without retroreflectors (208002) is much smaller than for targets with retroreflectors (877262), because these objects are non-reflective, irregularly shaped, are big and undergo a rotate/tumble motion. According to the DISCOS catalogue provided by ESA, all rocket bodies tracked by BORL station have a cylinder shape with height from 2 to $11 \mathrm{~m}$. There are two interesting objects-CZ2C-28480 and CZ2C-31114. They were observed by picosecond EKSPLA laser module and gave very good reflections, with RMS of about $2-10 \mathrm{~cm}$. Probably, these objects are equipped with reflective foil, which was confirmed independently by using this laser (Lejba et al, 2018). In 2016, the CZ2C-31114 was observed using nanosecond Continuum laser module, so the RMS is about $20 \mathrm{~cm}$. The used detection system is intended for International Laser Ranging Service (ILRS) (Pearlman et al., 2019) satellites (ILRS Current Missions, 2021), not for space debris. However, even the detector with quantum efficiency $(\mathrm{QE})$ on the level of $10 \%$ allows for laser measurements of defunct satellites and rocket bodies. How challenging is the laser tracking of such objects is very well presented in Figures 5-7 with the sample passes of some rocket bodies.

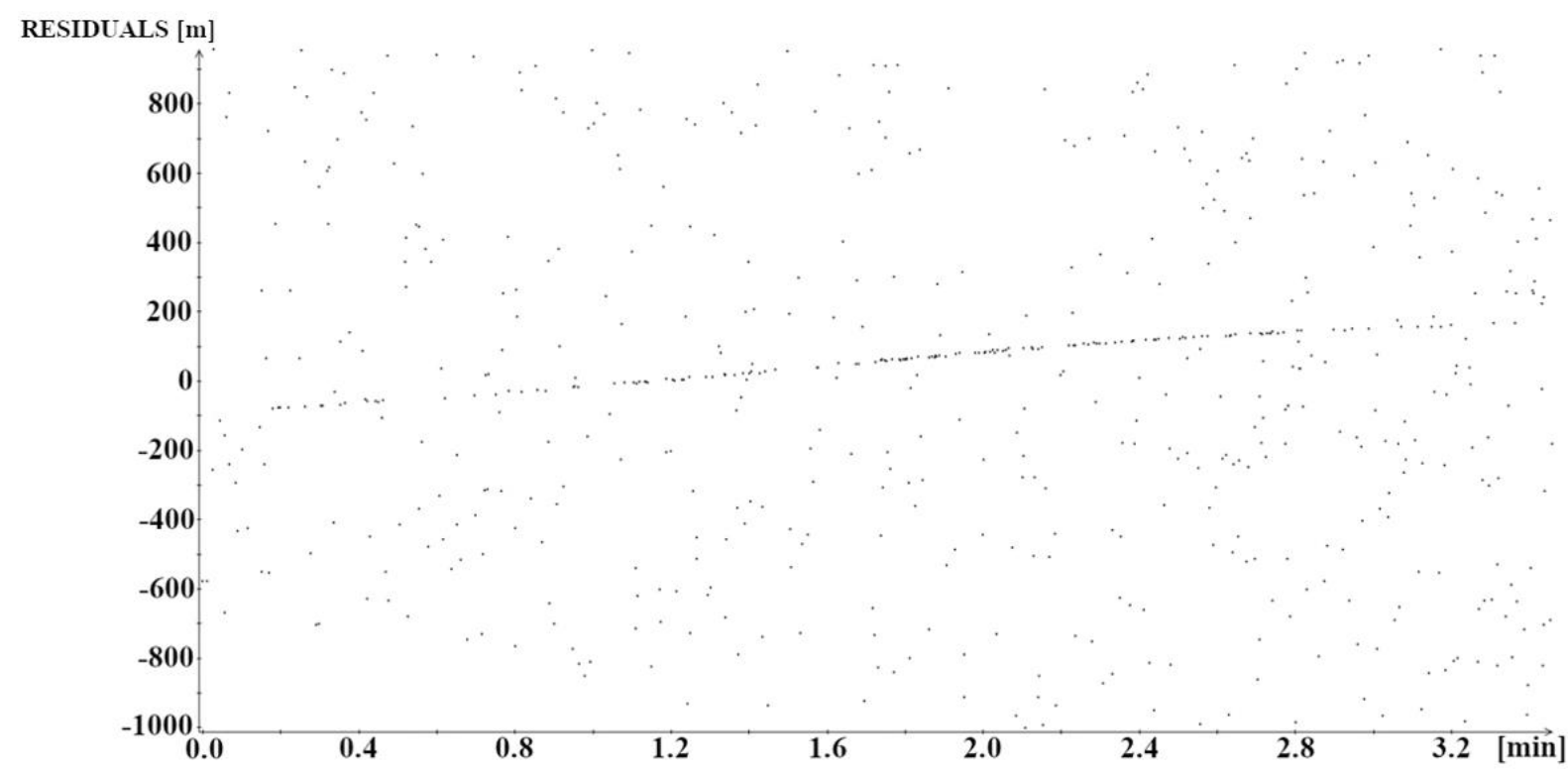

Figure 5. Registered pass of SL16RB target, NORAD 25861 on January 24, 2020 with 137 returns and 13 normal points. The pass RMS is $187.6 \mathrm{~cm}$. 


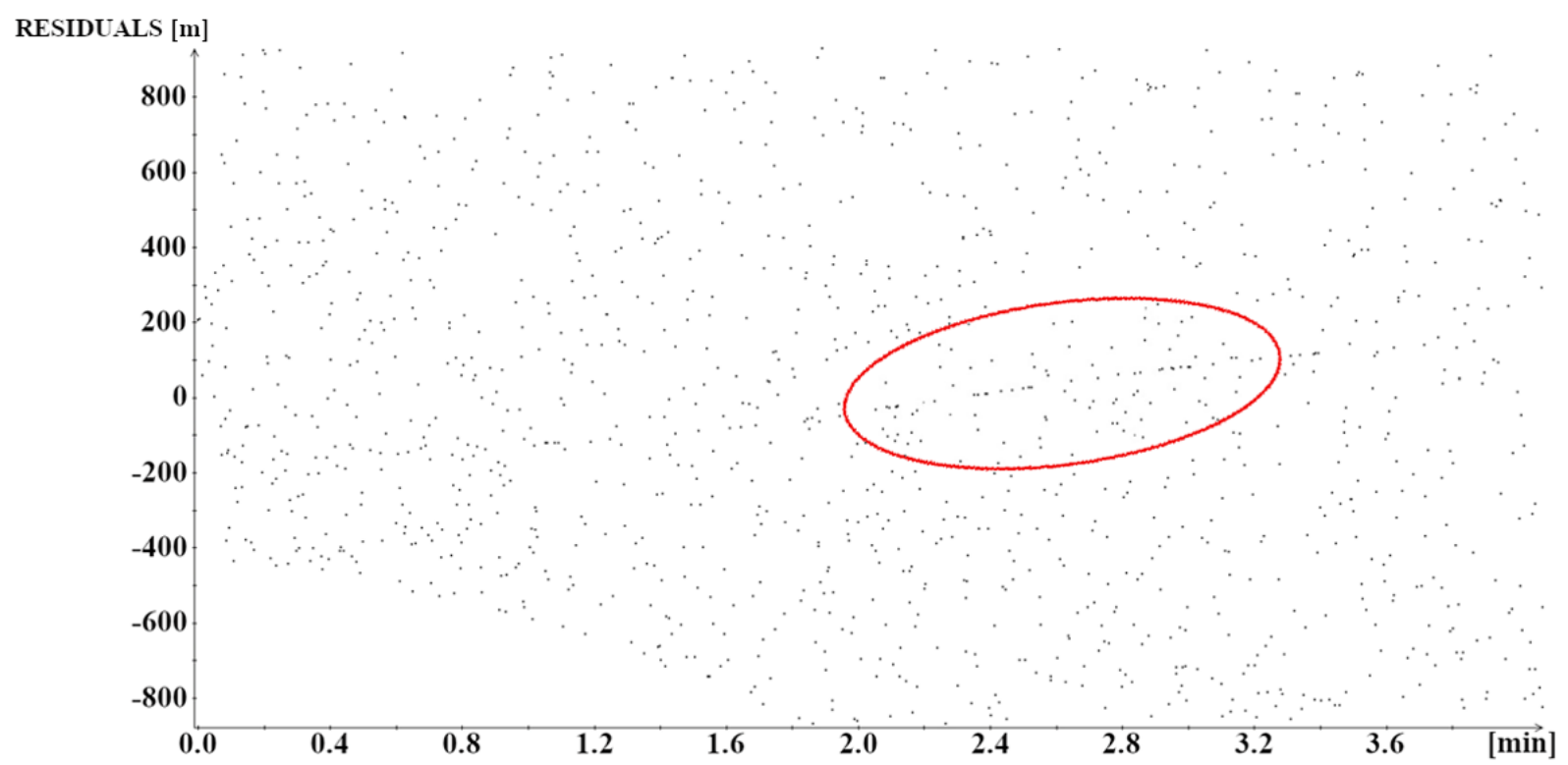

Figure 6. Registered pass of SL14RB target, NORAD 11267 on February 7, 2020 with 50 returns and 8 normal points. The pass RMS is $49.5 \mathrm{~cm}$.

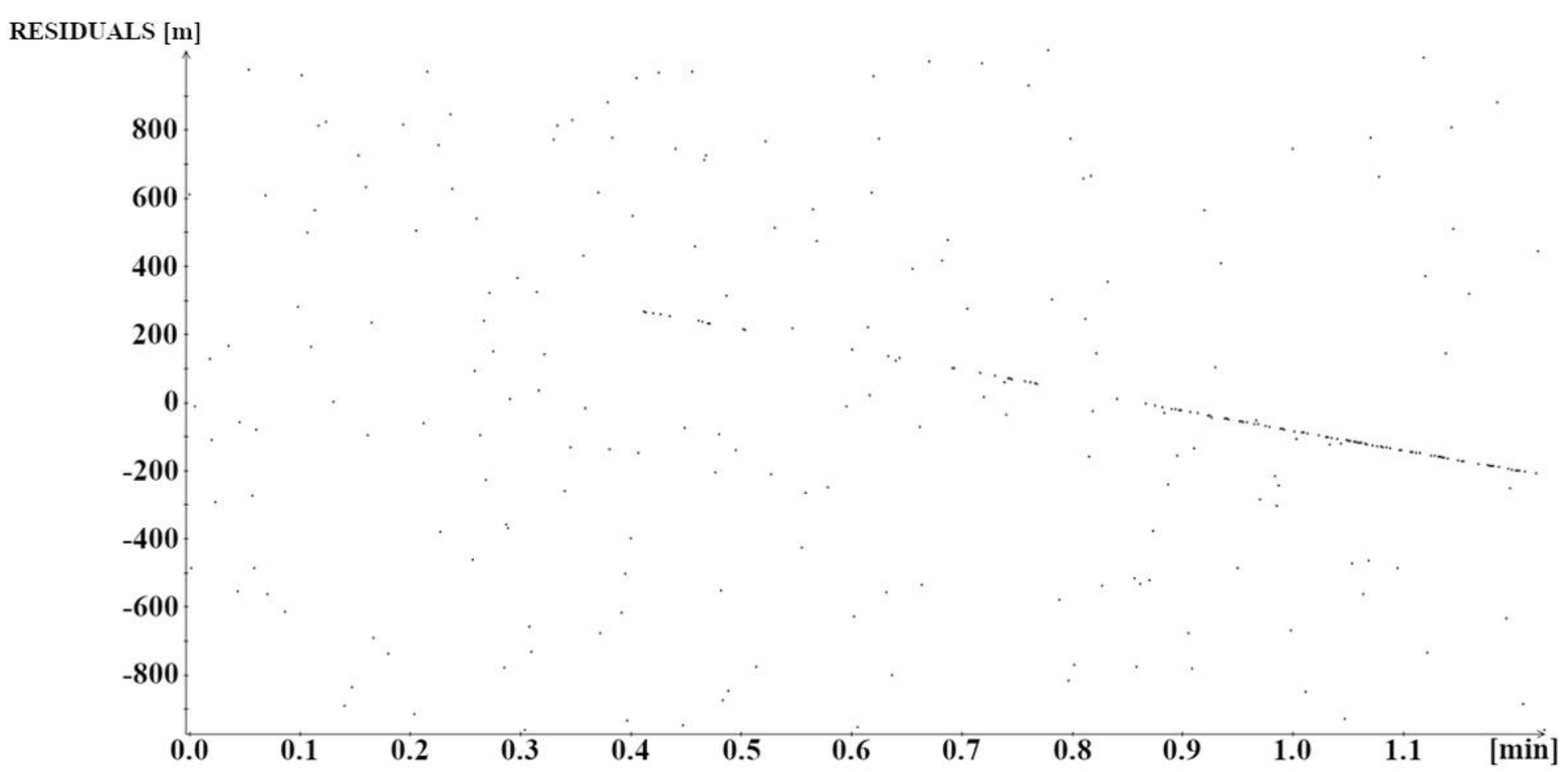

Figure 7. Registered pass of CZ2CRB target, NORAD 28222 on September 17, 2020 with 93 returns and 5 normal points. The pass RMS is $20.3 \mathrm{~cm}$.

Throughout 2016-2020, year to year, a major progress has been made with the number of tracked objects given by the increase of recorded passes and created normal points. In 2016, the Borowiec station tracked 43 LEO and MEO objects; in 2020, it was 130 objects, including space debris objects. Figures 8 and 9 show the numbers of successful passes and normal points in 2016-2020. 


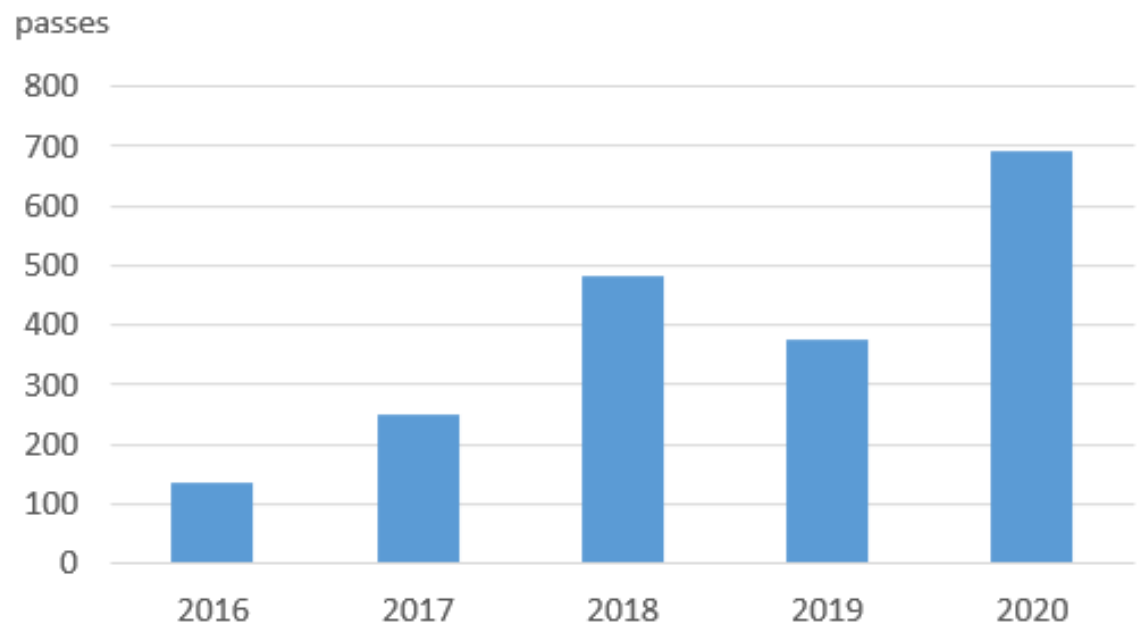

Figure 8. Number of registered passes of space debris observed by BORL station in years 2016-2020

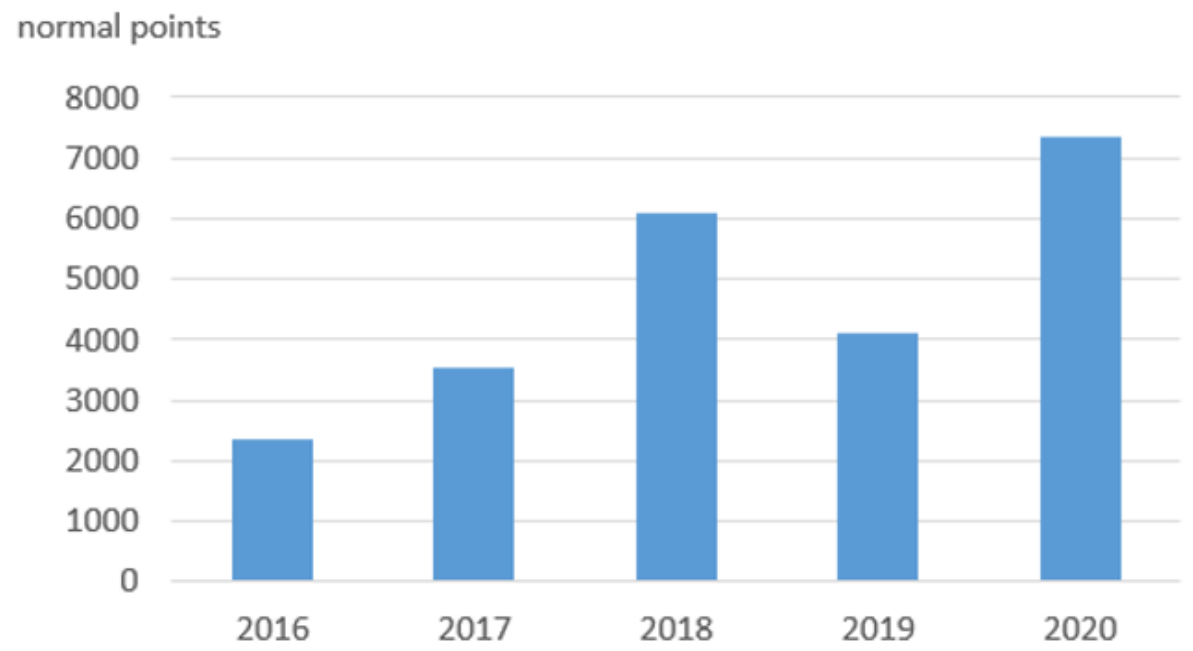

Figure 9. Number of registered normal points of space debris observed by BORL station in years 2016-2020

\section{SUMMARY AND CONCLUSIONS}

Over the five years (2016-2020), the Borowiec station (BORL 7811) successfully observed several dozens of space debris objects like inactive/defunct satellites: ADEOS-1 and ADEOS2, ENVISAT, ERS-1 and ERS-2, JASON-1, OICETS, SEASAT-1, TOPEX/Poseidon, and rocket bodies from LEO regime like: ARIANE, CZ, DELTA, SL or TITAN. The total sum of all registered passes of debris targets from five years is approximately 2000 , which gave over 23000 normal points. The most tracked object is TOPEX/Poseidon with the sum of all passes 378 , which contributes $20 \%$ to all passes. Average RMS of all objects equipped with retroreflectors ranges from 1.5 to $14 \mathrm{~cm}$. Average RMS of all objects without SLR-dedicated retroreflectors is from about $8 \mathrm{~cm}$ to even $222 \mathrm{~cm}$.

The main difficulty of the laser ranging to the space debris comes down to several important factors: the sensitivity of detection system efficiency, the laser pulse energy, the laser wavelength, repetition rate of the laser source, the effective area of the telescope, the efficiency of the optics and the quality of the input ephemerides (Degnan, 1993). No retroreflectors and other dedicated elements which can easily reflect the laser photons, size of the objects and their visibility, dynamic change of the orientation in space and distance to the objects are also very 
important. Another very important factor is the weather. Observations are impossible when the sky is covered by clouds. Furthermore, invisible space debris that are in the shadow of the Earth are very difficult to observe due to inaccurate ephemeris. More powerful laser with higher repetition rate and higher energy of the laser pulse and better detection system would increase the number of successful observations significantly. As results from the laser link equation given by John Degnan (Degnan, 1993), in comparison to the current laser system of the BORL station, the use of detector like Single-Photon Avalanche Diode (SPAD) and laser with the repetition rate of $100 \mathrm{~Hz}(0.45 \mathrm{~J}$ of pulse energy for $532 \mathrm{~nm})$ could improve the effectiveness of the tracking of space debris by approximately factor 80 .

The rocket bodies are more difficult to observe. This is presented in Appendix 2. Successful observations are very short; very often, the obtained reflections last several seconds. It is unknown what part of the target gives reflections from and centre of the mass is unknown too. Additionally, the space debris objects are still rotating/tumbling. When comparing the results of observations of rocket bodies with inactive satellites, large differences in the numbers of successful measurements can be seen. Thanks to nanosecond laser modules, the accuracy of laser measurements to space debris is much lower with respect to ranging of satellites equipped with retroreflectors. The RMS is on the level of $2-222 \mathrm{~cm}$. However, such values significantly improve the orbits of space debris objects, improve re-entry service and reduce the alert rate on orbital collision warnings, which is very crucial from the Space Surveillance and Tracking/Space Safety/Space Traffic Management programmes point of view.

\section{REFERENCES}

Degnan J.J. (1993). Millimeter Accuracy Satellite Laser Ranging: A Review, Contributions of Space Geodesy to Geodynamics: Technology, Geodynamics Series Vol. 25, 133-162.

Greene B., Gao Y., Moore C., Wang Y., Boiko A., Ritchie J., Sang J., Cotter J. (2002). Laser tracking of space debris, Proceedings of $13^{\text {th }}$ International Workshop on Laser Ranging, Washington D.C., Oct. 7-11, 2002.

Jagoda M., Rutkowska M. (2016). Estimation of the Love numbers: k2, k3 using SLR data of the LAGEOS1, LAGEOS2, STELLA and STARLETTE satellites, Acta Geodaetica et Geophysica, Vol. 51, No. 3, 493-504.

Jagoda M., Rutkowska M., Kraszewska K. (2016). The evaluation of time variability of tidal parameters h and 1 using SLR technique, Acta Geodynamica et Geomaterialia, Vol. 14, No. 2, $153-158$.

Kan S. (2007). China's Anti-Satellite Weapon Test, Congressional Research Service Report for Congress, April 23, 2007.

Kessler D.J., Cour-Palais B.G. (1978). Collision frequency of artificial satellites: the creation of a debris belt, Journal of Geophysical Research, 38 (A6), 2646-2647.

Kirchner G., Koidl F. (2015). Laser Ranging to Space Debris from Graz Laser Station, Vermessung \& Geoinformation, 2+3/2015, 151-155.

Kucharski D., Kirchner G., Bennett J.C., Lachut M., Sośnica K., Koshkin N., Shakun L., Koidl F., Steindorfer M., Wang P., Fan C., Han X., Grunwaldt L., Wilkinson M., Rodriguez J., Bianco G., Vespe F., Catalán M., Salmins K., del Pino J.R., Lim H.C., Park E., Moore C., Lejba P., Suchodolski T. (2017). Photon Pressure Force on Space Debris TOPEX/Poseidon Measured by Satellite Laser Ranging, Earth and Space Science, Vol. 4, Issue 10, 661- 668.

Kucharski D., Kirchner G., Otsubo T., Flegel S.K., Kunimori H., Jah M.K., Koidl F., Bennett J.C., Steindorfer M., Wang P. (2020). Quanta Photogrammetry of Experimental Geodetic 
Satellite for remote detection of micrometeoroid and orbital debris impacts, Acta Astronautica, Vol. 174, 34-31.

Lejba P., Schillak S. (2011). Determination of station positions and velocities from laser ranging observations to Ajisai, Starlette and Stella satellites, Advances in Space Research, Vol. 47, Issue 4, 654-662.

Lejba P., Suchodolski T., Schillak S., Bartoszak J., Michałek P., Zapaśnik S. (2016). New face of the Borowiec Satellite Laser Ranging Station, Proceedings of the $20^{\text {th }}$ International Workshop on Laser Ranging, Potsdam, Oct. 9-14.2016.

Lejba P., Suchodolski T., Michałek P., Bartoszak J., Schillak S., Zapaśnik S. (2018). First laser measurements to space debris in Poland, Advances in Space Research, Vol. 61, Issue 10, 2609-2616, DOI: https://doi.org/10.1016/j.asr.2018.02.033.

Lejba P., Suchodolski T., Michałek P. (2020). Laser Ranging to Space Debris in Poland: Tracking and Orbit Determination, The Advanced Maui Optical and Space Surveillance Technologies Conference (AMOS).

Milowicki G.V., Johnson-Freese J. (2008). Strategic Choices: Examining the United States Military Response to the Chinese Anti-Satellite Test, Astropolitics The International Journal of Space Politics and Policy, Vol. 6, No. 1, 1-21, DOI: https://doi.org/10.1080/14777620801907913.

Pearlman M.R., Noll C.E., Pavlis E.C., Lemoine F.G., Combrink L., Degnan J.J., Kirchner G., Schreiber U. (2019). The ILRS: approaching 20 years and planning for future, Journal of Geodesy, Vol. 93, 2161-2180, DOI: https://doi.org/10.1007/s00190-019-01241-1.

Schillak S. (2004). Analysis of the process of the determination of the station coordinaties by the satellite laser ranging based on results of the Borowiec SLR station in 1993.5-2000.5, Artificial Satellites, Vol. 39, No. 3, 217-287.

Schillak S., Lejba P., Michałek P. (2021). Analysis of the Quality of SLR Station Coordinates Determined from Laser Ranging to the LARES Satellite, Sensors, Vol. 21, Issue 3, 737.

Sośnica K., Thaller D., Jäggi A., Dach R., Beutler G. (2012). Sensitivity of LAGEOS orgits to global gravity field model, Artificial Satellites, Vol. 47, No. 2, 47-65.

Sośnica K., Jäggi A., Thaller D., Beutler G., Dach R. (2014). Contribution of Starlette, Stella, and Ajisai to the SLR-derived global reference frame, Journal of Geodesy, Vol. 88, No. 8, 789804.

Sośnica K. (2015). LAGEOS Sensitivity to Ocean Tides, Acta Geophysica, Vol. 63, No. 4, 1181-1203.

Steindorfer M.A., Kirchner G., Koidl F., Wang P., Kucharski D. (2019). Recent space debris related activities at the SLR station Graz, $1^{s t}$ NEO and Debris Detection Conference.

Steindorfer M.A., Kirchner G., Koidl F., Wang P., Jilate B., Flohrer T. (2020). Daylight space debris laser ranging, Nature Communications, Vol. 11(1), 3735, DOI: https://doi.org/10.1038/s41467-020-17332-Z.

Tagawa M., Hanada T., Hashimoto K., Kitazawa Y., Kawabe A. (2010). Orbital Debris Observation via Laser Illuminated Optical Measurement Techniques, Proceeding of the Advanced Maui Optical Space Surveillance Technologies Conference.

Wu Z., Zhang H., Deng H., Long M., Cheng Z., Zhang Z., Meng W. (2019). The progress of laser ranging technology at Shanghai Astronomical Observatory, Geodesy and Geodynamics, 10, Issue 6, 492-498. 
ESA, May 20, 2021,

https://www.esa.int/Safety_Security/Space_Debris/Space_debris_by_the_numbers.

EUSST, February 26, 2021, https://www.eusst.eu/about-us/.

ILRS Current Missions, November 24, 2021,

https://ilrs.gsfc.nasa.gov/missions/satellite_missions/current_missions/index.html.

ILRS Past Missions, July 28, 2021,

https://ilrs.gsfc.nasa.gov/missions/satellite_missions/past_missions/index.html.

SDSG, November 25, 2021, https://ilrs.gsfc.nasa.gov/network/newg/sdsg/index.html.

Received: 2021-09-08

Reviewed: 2021-10-22 (undisclosed name) and 2021-10-30 (undisclosed name)

Accepted: 2021-12-29 
Appendix 1. The space debris equipped with retroreflectors tracked in 2016-2020 by BORL station (E - laser EKSPLA)

\begin{tabular}{|c|c|c|c|c|c|c|c|c|c|c|}
\hline Period & Laser & NORAD & Object & $\begin{array}{c}\text { Perigee } \\
{[\mathrm{km}]}\end{array}$ & $\begin{array}{c}\text { Apogee } \\
{[\mathrm{km}]}\end{array}$ & $\begin{array}{c}\text { Inclination } \\
{[\mathrm{deg}]}\end{array}$ & Passes & Points & $\begin{array}{l}\text { avr. } \\
\text { RMS } \\
{[\mathrm{cm}]}\end{array}$ & $\begin{array}{l}\text { Normal } \\
\text { Points }\end{array}$ \\
\hline \multirow{6}{*}{2016} & E & 21574 & ERS-1 & 749 & 799 & 99 & 14 & 4254 & 3.4 & 113 \\
\hline & $\mathrm{E}$ & 23560 & ERS-2 & 502 & 506 & 99 & 4 & 1254 & 4.4 & 32 \\
\hline & $\mathrm{E}$ & 27386 & ENVISAT & 771 & 773 & 98 & 12 & 5920 & 3.6 & 155 \\
\hline & $\mathrm{E}$ & 26997 & JASON-1 & 1325 & 1340 & 66 & 33 & 21227 & 1.5 & 630 \\
\hline & $\mathrm{E}$ & 28809 & OICETS & 562 & 585 & 98 & 17 & 3828 & 4.2 & 198 \\
\hline & $\mathrm{E}$ & 22076 & TOPEX & 1338 & 1351 & 66 & 47 & 83165 & 47.7 & 1189 \\
\hline \multirow{7}{*}{2017} & E & 27597 & ADEOS-2 & 806 & 809 & 99 & 10 & 3673 & 7.3 & 80 \\
\hline & E & 10967 & SEASAT-1 & 752 & 754 & 108 & 17 & 23236 & 13.4 & 338 \\
\hline & $\mathrm{E}$ & 21574 & ERS-1 & 749 & 799 & 99 & 30 & 15242 & 6.1 & 305 \\
\hline & $\mathrm{E}$ & 27386 & ENVISAT & 771 & 773 & 98 & 10 & 13175 & 14.0 & 176 \\
\hline & $\mathrm{E}$ & 26997 & JASON-1 & 1325 & 1340 & 66 & 20 & 11884 & 5.2 & 415 \\
\hline & $\mathrm{E}$ & 28809 & OICETS & 562 & 585 & 98 & 17 & 1936 & 10.1 & 168 \\
\hline & $\mathrm{E}$ & 22076 & TOPEX & 1338 & 1351 & 66 & 51 & 94435 & 46.1 & 1263 \\
\hline \multirow{8}{*}{2018} & $\mathrm{E}$ & 27597 & ADEOS-2 & 806 & 809 & 99 & 29 & 8305 & 2.9 & 263 \\
\hline & E & 10967 & SEASAT-1 & 752 & 754 & 108 & 74 & 48347 & 4.1 & 1151 \\
\hline & E & 21574 & ERS-1 & 749 & 799 & 99 & 49 & 17561 & 2.6 & 529 \\
\hline & $\mathrm{E}$ & 23560 & ERS-2 & 502 & 506 & 99 & 9 & 1637 & 2.8 & 71 \\
\hline & $\mathrm{E}$ & 27386 & ENVISAT & 771 & 773 & 98 & 18 & 10360 & 4.3 & 261 \\
\hline & $\mathrm{E}$ & 26997 & JASON-1 & 1325 & 1340 & 66 & 27 & 13145 & 4.0 & 515 \\
\hline & $\mathrm{E}$ & 28809 & OICETS & 562 & 585 & 98 & 47 & 7471 & 3.2 & 587 \\
\hline & $\mathrm{E}$ & 22076 & TOPEX & 1338 & 1351 & 66 & 75 & 85615 & 44.8 & 1522 \\
\hline \multirow{8}{*}{2019} & $\mathrm{E}$ & 27597 & ADEOS-2 & 806 & 809 & 99 & 17 & 3367 & 3.3 & 118 \\
\hline & $\mathrm{E}$ & 27386 & ENVISAT & 771 & 773 & 98 & 17 & 10083 & 2.0 & 236 \\
\hline & $\mathrm{E}$ & 21574 & ERS-1 & 749 & 799 & 99 & 18 & 9916 & 3.6 & 237 \\
\hline & $\mathrm{E}$ & 23560 & ERS-2 & 502 & 506 & 99 & 16 & 2366 & 7.9 & 99 \\
\hline & $\mathrm{E}$ & 26997 & JASON-1 & 1325 & 1340 & 66 & 10 & 4086 & 3.9 & 166 \\
\hline & $\mathrm{E}$ & 28809 & OICETS & 562 & 585 & 98 & 44 & 6673 & 4.9 & 507 \\
\hline & $E$ & 10967 & SEASAT-1 & 752 & 754 & 108 & 44 & 29111 & 4.8 & 680 \\
\hline & $\mathrm{E}$ & 22076 & TOPEX & 1338 & 1351 & 66 & 61 & 62288 & 46.4 & 1140 \\
\hline \multirow{9}{*}{2020} & $\mathrm{E}$ & 24277 & ADEOS-1 & 799 & 802 & 99 & 1 & 413 & 5.8 & 5 \\
\hline & $\mathrm{E}$ & 27597 & ADEOS-2 & 806 & 809 & 99 & 40 & 9551 & 2.0 & 294 \\
\hline & $\mathrm{E}$ & 27386 & ENVISAT & 771 & 773 & 98 & 3 & 1395 & 1.4 & 42 \\
\hline & $\mathrm{E}$ & 21574 & ERS-1 & 749 & 799 & 99 & 35 & 15629 & 1.9 & 340 \\
\hline & $\mathrm{E}$ & 23560 & ERS-2 & 502 & 506 & 99 & 21 & 7433 & 2.6 & 179 \\
\hline & $E$ & 26997 & JASON-1 & 1325 & 1340 & 66 & 27 & 9919 & 1.5 & 415 \\
\hline & $\mathrm{E}$ & 28809 & OICETS & 562 & 585 & 98 & 46 & 7546 & 2.6 & 596 \\
\hline & $\mathrm{E}$ & 10967 & SEASAT-1 & 752 & 754 & 108 & 72 & 39148 & 3.7 & 926 \\
\hline & $\mathrm{E}$ & 22076 & TOPEX & 1338 & 1351 & 66 & 144 & 182668 & 50.1 & 2754 \\
\hline
\end{tabular}


Appendix 2. Objects without retroreflectors tracked in 2016 by BORL station (E - laser EKSPLA, C - laser Continuum)

\begin{tabular}{|c|c|c|c|c|c|c|c|c|c|c|}
\hline Period & Laser & NORAD & Object & $\begin{array}{c}\text { Perigee } \\
{[\mathrm{km}]}\end{array}$ & $\begin{array}{c}\text { Apogee } \\
{[\mathrm{km}]}\end{array}$ & $\begin{array}{c}\text { Inclination } \\
\text { [deg] }\end{array}$ & Passes & Points & $\begin{array}{l}\text { avr. } \\
\text { RMS } \\
{[\mathrm{cm}]}\end{array}$ & $\begin{array}{l}\text { Normal } \\
\text { Points }\end{array}$ \\
\hline \multirow{4}{*}{2016} & $\mathrm{E}$ & 31114 & CZ2C-31114 & 791 & 879 & 98 & 2 & 192 & 20.4 & 10 \\
\hline & $\mathrm{C}$ & 13121 & SL3-13121 & 841 & 857 & 71 & 1 & 18 & 8.0 & 3 \\
\hline & $\mathrm{C}$ & 17912 & SL14-17912 & 612 & 641 & 83 & 1 & 43 & 44.1 & 11 \\
\hline & $\mathrm{C}$ & 23088 & SL16-23088 & 847 & 854 & 71 & 4 & 243 & 75.3 & 14 \\
\hline \multirow{5}{*}{2017} & $\mathrm{E}$ & 28480 & CZ2C-28480 & 711 & 915 & 98 & 36 & 17830 & 8.7 & 259 \\
\hline & $\mathrm{E}$ & 31114 & CZ2C-31114 & 791 & 879 & 98 & 56 & 49335 & 9.4 & 502 \\
\hline & $\mathrm{C}$ & 17912 & SL14-17912 & 612 & 641 & 83 & 1 & 21 & 41.7 & 4 \\
\hline & $\mathrm{C}$ & 23088 & SL16-23088 & 847 & 854 & 71 & 2 & 127 & 39.4 & 16 \\
\hline & $\mathrm{C}$ & 23705 & SL16-23705 & 841 & 857 & 71 & 1 & 7 & 81.6 & 3 \\
\hline \multirow{2}{*}{2018} & $\mathrm{E}$ & 28480 & CZ2C-28480 & 711 & 915 & 98 & 39 & 12424 & 2.5 & 227 \\
\hline & $\mathrm{E}$ & 31114 & CZ2C-31114 & 791 & 879 & 98 & 116 & 74287 & 3.9 & 959 \\
\hline \multirow{30}{*}{2019} & $\mathrm{C}$ & 21610 & ARN-21610 & 760 & 766 & 99 & 1 & 12 & 81.6 & 3 \\
\hline & $\mathrm{C}$ & 23561 & ARN-23561 & 767 & 778 & 99 & 3 & 56 & 50.4 & 23 \\
\hline & $\mathrm{C}$ & 28222 & CZ2C-28222 & 510 & 575 & 98 & 5 & 621 & 17.7 & 29 \\
\hline & $\mathrm{E}$ & 28480 & CZ2C-28480 & 711 & 915 & 98 & 24 & 7930 & 10.7 & 125 \\
\hline & $E$ & 31114 & CZ2C-31114 & 791 & 879 & 98 & 50 & 21557 & 3.8 & 308 \\
\hline & $\mathrm{C}$ & 33323 & CZ2C-33323 & 590 & 626 & 98 & 1 & 30 & 48.8 & 8 \\
\hline & $\mathrm{C}$ & 37731 & CZ2C-37731 & 611 & 697 & 98 & 3 & 172 & 127.7 & 24 \\
\hline & $\mathrm{C}$ & 37766 & CZ2C-37766 & 647 & 712 & 98 & 2 & 28 & 22.2 & 8 \\
\hline & $\mathrm{C}$ & 39203 & CZ2C-39203 & 681 & 753 & 99 & 2 & 50 & 81.6 & 16 \\
\hline & $\mathrm{C}$ & 39364 & CZ2C-39364 & 460 & 524 & 97 & 4 & 101 & 45.6 & 17 \\
\hline & $\mathrm{C}$ & 39625 & CZ2C-39625 & 474 & 671 & 98 & 5 & 246 & 93.9 & 42 \\
\hline & $\mathrm{C}$ & 39211 & CZ4C-39211 & 471 & 644 & 98 & 2 & 49 & 30.0 & 7 \\
\hline & $\mathrm{C}$ & 29507 & CZ4-29507 & 539 & 605 & 98 & 5 & 88 & 44.8 & 25 \\
\hline & $\mathrm{C}$ & 20323 & DLT1-20323 & 687 & 790 & 97 & 1 & 7 & 146.0 & 2 \\
\hline & $\mathrm{C}$ & 12904 & SL3-12904 & 537 & 576 & 81 & 1 & 29 & 31.2 & 3 \\
\hline & $\mathrm{C}$ & 13121 & SL3-13121 & 536 & 558 & 81 & 3 & 67 & 47.8 & 10 \\
\hline & $\mathrm{C}$ & 20775 & SL8-20775 & 374 & 1195 & 83 & 2 & 95 & 68.6 & 21 \\
\hline & $\mathrm{C}$ & 15772 & SL12-15772 & 802 & 855 & 71 & 1 & 32 & 55.5 & 12 \\
\hline & $\mathrm{C}$ & 18749 & SL14-18749 & 612 & 641 & 83 & 3 & 41 & 48.9 & 10 \\
\hline & $\mathrm{C}$ & 19275 & SL14-19275 & 614 & 642 & 83 & 1 & 40 & 45.9 & 5 \\
\hline & $\mathrm{C}$ & 20511 & SL14-20511 & 625 & 648 & 83 & 3 & 67 & 24.2 & 21 \\
\hline & $\mathrm{C}$ & 16182 & SL16-16182 & 838 & 852 & 71 & 1 & 21 & 80.2 & 7 \\
\hline & $\mathrm{C}$ & 17590 & SL16-17590 & 840 & 846 & 71 & 1 & 11 & 144.2 & 4 \\
\hline & $\mathrm{C}$ & 19650 & SL16-19650 & 838 & 856 & 71 & 2 & 43 & 107.4 & 18 \\
\hline & $\mathrm{C}$ & 22220 & SL16-22220 & 837 & 852 & 71 & 4 & 94 & 30.9 & 33 \\
\hline & $\mathrm{C}$ & 22803 & SL16-22803 & 830 & 857 & 71 & 4 & 122 & 78.9 & 30 \\
\hline & $\mathrm{C}$ & 23705 & SL16-23705 & 841 & 857 & 71 & 1 & 98 & 221.7 & 8 \\
\hline & $\mathrm{C}$ & 25400 & SL16-25400 & 806 & 822 & 99 & 6 & 228 & 51.8 & 62 \\
\hline & $\mathrm{C}$ & 25861 & SL16-25861 & 631 & 651 & 98 & 3 & 280 & 112.5 & 28 \\
\hline & $\mathrm{C}$ & 26474 & TTN-26474 & 544 & 629 & 68 & 4 & 129 & 111.6 & 23 \\
\hline
\end{tabular}




\begin{tabular}{|c|c|c|c|c|c|c|c|c|c|c|}
\hline Period & Laser & NORAD & Object & $\begin{array}{c}\text { Perigee } \\
{[\mathrm{km}]}\end{array}$ & $\begin{array}{c}\text { Apogee } \\
{[\mathrm{km}]}\end{array}$ & $\begin{array}{c}\text { Inclination } \\
{[\mathrm{deg}]}\end{array}$ & Passes & Points & $\begin{array}{c}\text { avr. } \\
\text { RMS } \\
{[\mathrm{cm}]}\end{array}$ & $\begin{array}{c}\text { Normal } \\
\text { Points }\end{array}$ \\
\hline \multirow{44}{*}{2020} & C & 21610 & ARN-21610 & 760 & 766 & 99 & 8 & 175 & 101.4 & 50 \\
\hline & $\mathrm{C}$ & 23561 & ARN-23561 & 767 & 778 & 99 & 5 & 205 & 60.9 & 52 \\
\hline & $\mathrm{C}$ & 28222 & CZ2C-28222 & 510 & 575 & 98 & 6 & 1424 & 45.5 & 43 \\
\hline & $\mathrm{E}$ & 28480 & CZ2C-28480 & 711 & 915 & 98 & 11 & 2853 & 11.0 & 54 \\
\hline & $\mathrm{E}$ & 31114 & CZ2C-31114 & 791 & 879 & 98 & 29 & 9792 & 1.9 & 146 \\
\hline & $\mathrm{C}$ & 33323 & CZ2C-33323 & 590 & 626 & 98 & 1 & 25 & 47.0 & 10 \\
\hline & $\mathrm{C}$ & 36089 & CZ2C-36089 & 674 & 793 & 98 & 1 & 27 & 55.5 & 8 \\
\hline & $\mathrm{C}$ & 37731 & CZ2C-37731 & 611 & 697 & 98 & 5 & 122 & 60.2 & 27 \\
\hline & $\mathrm{C}$ & 37766 & CZ2C-37766 & 647 & 712 & 98 & 5 & 136 & 113.7 & 45 \\
\hline & $\mathrm{C}$ & 39203 & CZ2C-39203 & 681 & 753 & 99 & 7 & 146 & 60.9 & 37 \\
\hline & $\mathrm{C}$ & 39364 & CZ2C-39364 & 460 & 524 & 97 & 5 & 166 & 107.7 & 33 \\
\hline & $\mathrm{C}$ & 39625 & CZ2C-39625 & 474 & 671 & 98 & 9 & 114 & 73.3 & 34 \\
\hline & $\mathrm{C}$ & 40287 & CZ2C-40287 & 680 & 692 & 98 & 8 & 168 & 73.3 & 40 \\
\hline & $\mathrm{C}$ & 43610 & CZ2C-43610 & 787 & 99 & 99 & 5 & 81 & 27.4 & 23 \\
\hline & $\mathrm{C}$ & 29093 & CZ4B-29093 & 398 & 474 & 98 & 1 & 8 & 28.7 & 2 \\
\hline & $\mathrm{C}$ & 39211 & CZ4C-39211 & 471 & 644 & 98 & 5 & 93 & 45.6 & 20 \\
\hline & $\mathrm{C}$ & 20323 & DLT1-20323 & 687 & 790 & 97 & 4 & 67 & 75.0 & 28 \\
\hline & $\mathrm{C}$ & 877 & SL3-00877 & 659 & 745 & 65 & 4 & 62 & 36.3 & 18 \\
\hline & $\mathrm{C}$ & 4814 & SL3-04814 & 450 & 484 & 81 & 3 & 82 & 19.8 & 14 \\
\hline & $\mathrm{C}$ & 5118 & SL3-05118 & 496 & 563 & 81 & 3 & 86 & 43.6 & 21 \\
\hline & $\mathrm{C}$ & 7004 & SL3-07004 & 313 & 437 & 74 & 1 & 61 & 65.8 & 4 \\
\hline & $\mathrm{C}$ & 12465 & SL3-12465 & 505 & 553 & 81 & 7 & 233 & 36.0 & 34 \\
\hline & $\mathrm{C}$ & 12904 & SL3-12904 & 537 & 576 & 81 & 7 & 201 & 34.1 & 28 \\
\hline & $\mathrm{C}$ & 13121 & SL3-13121 & 536 & 558 & 81 & 6 & 215 & 33.7 & 26 \\
\hline & $\mathrm{C}$ & 13771 & SL3-13771 & 514 & 569 & 81 & 19 & 620 & 37.8 & 61 \\
\hline & $\mathrm{C}$ & 13819 & SL3-13819 & 503 & 548 & 81 & 3 & 59 & 23.9 & 16 \\
\hline & $\mathrm{C}$ & 20775 & SL8-20775 & 374 & 1195 & 83 & 3 & 67 & 38.9 & 21 \\
\hline & $\mathrm{C}$ & 15772 & SL12-15772 & 802 & 855 & 71 & 3 & 60 & 31.3 & 19 \\
\hline & $\mathrm{C}$ & 11267 & SL14-11267 & 597 & 620 & 83 & 5 & 133 & 28.3 & 26 \\
\hline & $\mathrm{C}$ & 14820 & SL14-14820 & 613 & 637 & 83 & 2 & 42 & 27.5 & 12 \\
\hline & $\mathrm{C}$ & 17912 & SL14-17912 & 612 & 641 & 83 & 7 & 182 & 32.8 & 31 \\
\hline & $\mathrm{C}$ & 18749 & SL14-18749 & 612 & 641 & 83 & 1 & 13 & 18.1 & 3 \\
\hline & $\mathrm{C}$ & 19275 & SL14-19275 & 614 & 642 & 83 & 5 & 103 & 22.3 & 24 \\
\hline & $\mathrm{C}$ & 20511 & SL14-20511 & 625 & 648 & 83 & 6 & 83 & 19.7 & 22 \\
\hline & $\mathrm{C}$ & 16182 & SL16-16182 & 838 & 852 & 71 & 8 & 251 & 89.0 & 55 \\
\hline & $\mathrm{C}$ & 17590 & SL16-17590 & 840 & 846 & 71 & 9 & 193 & 88.4 & 63 \\
\hline & $\mathrm{C}$ & 19650 & SL16-19650 & 838 & 856 & 71 & 4 & 86 & 68.5 & 24 \\
\hline & $\mathrm{C}$ & 20625 & SL16-20625 & 839 & 862 & 71 & 7 & 217 & 121.7 & 62 \\
\hline & $\mathrm{C}$ & 22220 & SL16-22220 & 837 & 852 & 71 & 13 & 520 & 74.5 & 123 \\
\hline & $\mathrm{C}$ & 22803 & SL16-22803 & 830 & 857 & 71 & 10 & 318 & 108.9 & 101 \\
\hline & $\mathrm{C}$ & 23088 & SL16-23088 & 847 & 854 & 71 & 6 & 91 & 62.6 & 18 \\
\hline & $\mathrm{C}$ & 23343 & SL16-23343 & 643 & 651 & 98 & 5 & 107 & 106.6 & 15 \\
\hline & $\mathrm{C}$ & 23705 & SL16-23705 & 841 & 857 & 71 & 10 & 288 & 105.6 & 47 \\
\hline & $\mathrm{C}$ & 25400 & SL16-25400 & 806 & 822 & 99 & 14 & 526 & 80.3 & 130 \\
\hline
\end{tabular}




\begin{tabular}{|c|c|c|c|c|c|c|c|c|c|c|}
\hline Period & Laser & NORAD & Object & $\begin{array}{c}\text { Perigee } \\
{[\mathrm{km}]}\end{array}$ & $\begin{array}{c}\text { Apogee } \\
{[\mathrm{km}]}\end{array}$ & $\begin{array}{c}\text { Inclination } \\
{[\mathrm{deg}]}\end{array}$ & Passes & Points & $\begin{array}{c}\text { avr. } \\
\text { RMS } \\
{[\mathrm{cm}]}\end{array}$ & $\begin{array}{c}\text { Normal } \\
\text { Points }\end{array}$ \\
\hline \multirow{2}{*}{2020} & $\mathrm{C}$ & 25407 & SL16-25407 & 842 & 851 & 71 & 11 & 352 & 108.8 & 94 \\
\cline { 2 - 11 } & $\mathrm{C}$ & 25861 & SL16-25861 & 631 & 651 & 98 & 1 & 137 & 187.6 & 13 \\
\cline { 2 - 11 } & $\mathrm{C}$ & 26474 & TTN-26474 & 544 & 629 & 68 & 5 & 141 & 162.2 & 24 \\
\hline
\end{tabular}

